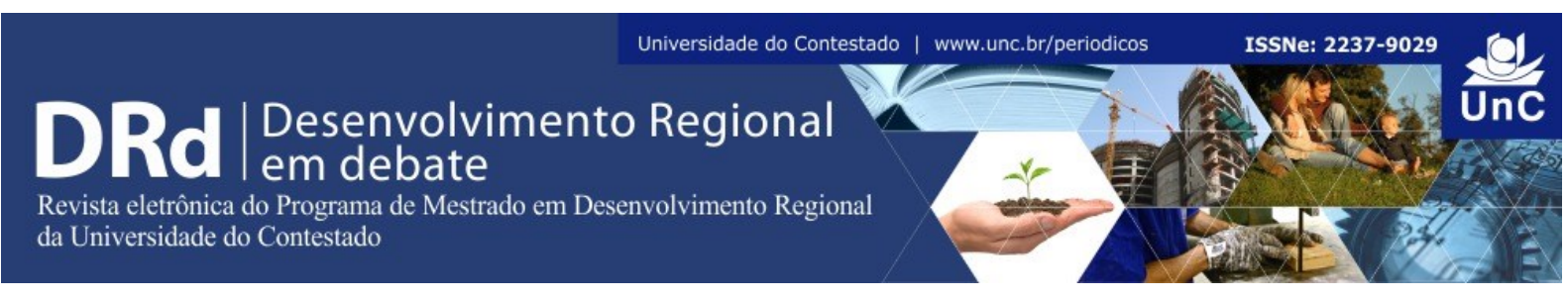

\title{
SYSCHAPADA: Sistema Web como Instrumento de Potencialização para o Desenvolvimento Territorial na Chapada Diamantina
}

Henrique Oliveira de Andrade ${ }^{1}$ Adilson Oliveira de Almirante ${ }^{2}$ Jéfte Batista de Oliveira ${ }^{3}$

\begin{abstract}
RESUMO
Este trabalho tem como objetivo evidenciar o poder de acesso à informação e geração do conhecimento de um sistema web, denominado de SysChapada (www.syschapada.ifba.edu.br), que contém informações acerca do Território de Identidade e do Colegiado de Desenvolvimento Territorial da Chapada Diamantina. No que se refere à metodologia, o trabalho contempla um estudo teórico-descritivo sobre a Política de Desenvolvimento Territorial (PDT) no Brasil e na Bahia, o Território de Identidade da Chapada Diamantina e o uso das Tecnologias da Informação e Comunicação aplicadas ao contexto do desenvolvimento territorial. As considerações finais são de que as ferramentas de tecnologia no contexto do desenvolvimento territorial são pouco utilizadas, por serem complexas e não possuírem usabilidade, desse modo, a forma como foi construída o SysChapada, o credencia como um sistema acessível e usável, que irá contribuir para potencializar desenvolvimento territorial na Chapada Diamantina, servindo como referência no contexto da PDT.
\end{abstract}

Palavras-chave: Política de Desenvolvimento Territorial. Chapada Diamantina. Desenvolvimento de Sistemas Web.

\section{SYSCHAPADA: A WEB SYSTEM AS AN INSTRUMENT OF POTENTIALIZATION FOR TERRITORIAL DEVELOPMENT AT CHAPADA DIAMANTINA}

\begin{abstract}
This paper aims to describe and present the processes and steps taken to create a Web System with information about the Territory of Identity and the Territorial Development group of Chapada Diamantina, which is called SysChapada. Considering the methodology, the paper includes a theoretical-descriptive study based on the conceptual and bibliographic bases that focus on questions about the Web Systems construction process and the description of the tools used. The paper also carries out a theoretical research in the Territorial Development Policy (PDT) in Brazil and at Bahia State, the Identity Territory of Chapada Diamantina and

\footnotetext{
${ }^{1}$ Mestre em Geografia pela UFBA. Professor EBTT do Instituto Federal de Educação, Ciência e Tecnologia da Bahia, IFBA campus Seabra. Seabra, Bahia, Brasil. E-mail: henriqueoliveira@ifba.edu.br

${ }^{2}$ Especialista em Redes de Computadores. Professor EBTT do Instituto Federal de Educação, Ciência e Tecnologia da Bahia, IFBA campus Seabra. Seabra, Bahia, Brasil. E-mail: adilsonalmirante@ifba.edu.br ${ }^{3}$ Estudante egresso do Instituto Federal de Educação, Ciência e Tecnologia da Bahia, IFBA campus Seabra. Seabra, Bahia, Brasil. E-mail: jeftebatista@ifba.edu.br
}

DRd - Desenvolvimento Regional em debate (ISSNe 2237-9029)

v. 7, n. 2, p. 76-95, jul./dez. 2017. 
the use of Information and Communication Technologies applied to the context of territorial development. The conclusions are that the technology tools in the context of territorial development are little used, because they are complex and have no utility, thus, the way in which SysChapada was built gives it the acknowledgment as an accessible and usable system, that will enhance the Territorial development at Chapada Diamantina, serving as a model of digital inclusion in PDT.

Keywords: Territorial Development Policy. Chapada Diamantina. Web Systems Development.

\section{INTRODUÇÃO}

A implementação da política nacional de apoio ao desenvolvimento sustentável dos territórios rurais foi resultado de um processo de acúmulos e de reivindicações de setores públicos e organizações da sociedade civil, que avaliaram como sendo necessária a articulação de políticas nacionais com iniciativas locais, segundo uma abordagem inovadora. Como resultado disso no início do governo de Luiz Inácio Lula da Silva (2003-2010), se teve a criação da Secretaria de Desenvolvimento Territorial (SDT), vinculada ao Ministério do Desenvolvimento Agrário (MDA). Esta Secretaria implementou a política pública de desenvolvimento territorial por meio do Programa Desenvolvimento Sustentável dos Territórios Rurais (PRONAT) buscando promover cada vez mais o protagonismo dos atores sociais para a construção e governança do desenvolvimento de seus territórios. Em 2008, visando ampliar o escopo do PRONAT, foi criado o Programa Territórios da Cidadania (PTC) (BRASIL, 2003; 2005).

Como resultado da política nacional de desenvolvimento territorial, em 2003 houve a criação do Colegiado de Desenvolvimento Territorial do território de identidade da Chapada Diamantina/BA, por parte de organizações representativas e movimentos sociais do meio rural. O Colegiado é uma institucionalidade que congrega as organizações da sociedade civil e as esferas do poder público, sendo responsável por executar a gestão social do desenvolvimento territorial (BRASIL, 2005). Desde então esse espaço de governança territorial vem se configurando como uma importante ferramenta de promoção da democracia participativa, de diagnóstico da realidade local e transformação social.

Concomitante a esse processo de fortalecimento da Política de Desenvolvimento Territorial (PDT), se intensificou o processo de avanço das Tecnologias de Informação e Comunicação (TIC) e segundo Castells (1999), vivemos em uma sociedade informacional. A sociedade da informação é a sociedade que está atualmente a constituir-se, na qual são amplamente utilizadas tecnologias de armazenamento e transmissão de dados e informação de baixo custo. A velocidade das transformações na sociedade da informação é impulsionada pelo desenvolvimento tecnológico, que tem como um de seus marcos a criação e difusão da internet. Assim, muitas pessoas e organizações aprenderam a usá-la em seu benefício, a partir do compartilhamento e publicação de informações, via computadores conectados numa rede capaz de abranger lugares geograficamente distribuídos. 
A política de desenvolvimento territorial através de seus instrumentos seguiu o caminho dessa informatização da sociedade, sua proposta de comunicação do MDA é digital, pois, a sua base está no uso de TICs para viabilizar as condições básicas de participação, organização, planejamento, articulação e controle social. Para isso prevê o livre acesso às informações e a interação entre os participantes. Nesse sentido, considera-se que as TICs promovem a participação cidadã na gestão de políticas públicas e contribuem para a ampliação do direito à informação, duas importantes características de um processo democrático republicano. Sabe-se, porém, que ainda existe um abismo social entre os cidadãos brasileiros, que resulta em diferentes níveis de acesso à informação.

A PDT possui duas ferramentas principais de acesso à informação e a comunicação, o Sistema de Gestão Estratégica (SGE) e o Portal da Cidadania (www.territoriosdacidadania.gov.br). O SGE e o Portal da Cidadania, são sistemas com grande quantidade e fluxos de informações disponíveis, o que acaba tornando os mesmos como ferramentas subutilizadas pelos atores sociais envolvidos no desenvolvimento territorial (ALLEBRANDT, 2012; 2015). Diante desse quadro vale citar Martino (2014, p. 87), quando ele fala sobre a exclusão digital não apenas como uma questão de acesso às Tecnologias de Informação e Comunicação, mas "[...] saber utilizar a rede, encontrar informações e transformá-las em conhecimento também pode ser um fator de exclusão digital".

Nessa perspectiva o objetivo deste trabalho é evidenciar o poder de acesso à informação e geração do conhecimento de uma ferramenta web, cujo intuito é ser uma ferramenta dinâmica, acessível e simples com informações acerca da caracterização geral do território de identidade da Chapada Diamantina, sobre o colegiado de desenvolvimento territorial deste território, suas instâncias de gestão e a política de desenvolvimento territorial de uma maneira geral. Assim, por meio deste diferencial de acessibilidade, associado ao conjunto de dados e informações disponíveis deseja-se possibilitar a comunicação e a discussão acerca dos problemas locais.

\section{MATERIAL E MÉTODOS}

O trabalho em questão contempla um estudo teórico-descritivo, com base nos fundamentos conceituais e bibliográficos que enfocam questões sobre o processo de construção de sistemas web e na descrição do sistema aqui apresentado. Para tal, inicialmente, revisa-se a literatura contemporânea sobre o tema e as ferramentas mais utilizadas no mercado, conforme as secções a seguir, além de uma pesquisa teórica sobre a Política de Desenvolvimento Territorial no Brasil e na Bahia, o Território de Identidade da Chapada Diamantina e o uso das Tecnologias da Informação e Comunicação aplicadas ao contexto do desenvolvimento territorial. 


\subsection{MATERIAIS}

Para o desenvolvimento das etapas de construção de softwares em geral, foi necessário o uso de ferramentas e tecnologias. Deste modo, o quadro a seguir apresenta as ferramentas utilizadas para modelar e implementar o sistema aqui descrito. Todas as tecnologias e ferramentas utilizadas no desenvolvimento deste sistema são gratuitas e muito utilizadas atualmente no mercado.

Quadro 1 - Ferramentas e tecnologias utilizadas

\begin{tabular}{|c|c|c|c|}
\hline $\begin{array}{l}\text { Ferramenta/ } \\
\text { Tecnologia: }\end{array}$ & Versão: & Finalidade: & Referência: \\
\hline $\begin{array}{l}\text { Astah } \\
\text { Professional }\end{array}$ & 7.0 .0 & $\begin{array}{l}\text { Modelagem do diagrama UML } \\
\text { com o diagrama de classes e de } \\
\text { casos de uso. }\end{array}$ & http://astah.net/editions/professional \\
\hline TerraER & 2.23 & $\begin{array}{l}\text { Criação da modelagem do modelo } \\
\text { entidade-relacionamento do } \\
\text { banco de dados. }\end{array}$ & http://www.terraer.com.br/ \\
\hline $\begin{array}{l}\text { MySql } \\
\text { Workbench }\end{array}$ & 6.3 .6 & $\begin{array}{l}\text { Criação da modelagem do modelo } \\
\text { relacional do banco de dados e do } \\
\text { script SQL. }\end{array}$ & https://www.mysql.com/products/workbench/ \\
\hline Notepad ++ & 6.8 .2 & Ambiente de desenvolvimento. & http://notepad-plus-plus.org/ \\
\hline PHP & 5.6 .12 & Linguagem de programação & http://php.net/ \\
\hline $\begin{array}{l}\text { Apache } \\
\text { Tomcat }\end{array}$ & 6.0 & Servidor web & http://tomcat.apache.org/ \\
\hline MySQL & 5.5 & Gerenciador de banco de dados & http://www.mysql.com/ \\
\hline XAMPP & 3.2 .1 & Ambiente integrado de testes & https://www.apachefriends.org/pt br/index.html \\
\hline HTML & 5 & $\begin{array}{l}\text { Linguagem de marcação utilizada } \\
\text { para produzir páginas na web }\end{array}$ & http://www.w3schools.com/html/ \\
\hline CSS & 3 & $\begin{array}{l}\text { Linguagem de estilo utilizada } \\
\text { para definir a apresentação de } \\
\text { documentos escritos em uma } \\
\text { linguagem de marcação }\end{array}$ & http://www.w3schools.com/css/ \\
\hline Bootstrap & 3.3 .6 & $\begin{array}{l}\text { Biblioteca CSS para conferir } \\
\text { estilos ao site }\end{array}$ & http://getbootstrap.com.br/ \\
\hline JavaScript & 5 & $\begin{array}{l}\text { Linguagem de programação } \\
\text { interpretada }\end{array}$ & http://www.w3schools.com/js/ \\
\hline Jquery & 1.9 .1 & $\begin{array}{l}\text { Biblioteca JavaScript de código } \\
\text { aberto }\end{array}$ & http://jquery.com/ \\
\hline PhpMyAdmin & 4.0 .8 & $\begin{array}{l}\text { Para gerenciamento do banco de } \\
\text { dados MySQL }\end{array}$ & $\begin{array}{l}\text { http://www.phpmyadmin.net/hom } \\
\text { e page/index.php }\end{array}$ \\
\hline
\end{tabular}

Fonte: Próprio autor (2017)

\subsection{MÉTODOS}

O trabalho aqui exposto está embasado em fundamentos e técnicas da Engenharia de Software, descritas nas etapas do seu desenvolvimento: definição do ciclo de vida, com o levantamento e a análise dos requisitos, e na modelagem do sistema, através da linguagem 
de modelagem orientada a objetos, Unified Modeling Language (UML). Estas etapas são fundamentais para o desenvolvimento do sistema, pois deram embasamento à construção da modelagem do banco de dados e também ao desenvolvimento do software. A metodologia seguida na criação do sistema web está exposta na figura a seguir.

Figura 1 - Ilustração gráfica da metodologia adotada construção do SysChapada

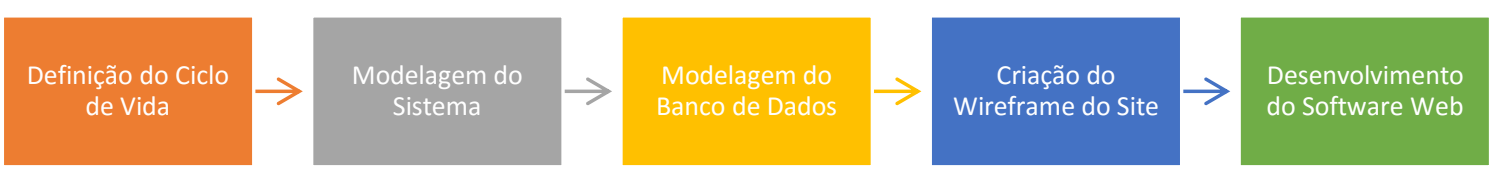

Fonte: Próprio Autor (2017).

No que se refere a metodologia empregada para o levantamento dos requisitos que o sistema deve atender, utilizou-se da técnica de entrevistas, onde foram entrevistados o coordenador do Colegiado de Desenvolvimento Territorial (CODETER) da Chapada Diamantina e o coordenador do Núcleo de Extensão em Desenvolvimento Territorial (NEDET) da Chapada Diamantina.

\section{POLÍTICA DE DESENVOLVIMENTO TERRITORIAL}

O Brasil é constituído por uma sociedade multicultural, na qual se estabelecem múltiplas relações de poder. Segundo Brandão (2007), é nítido que devido à grande extensão territorial do país, há necessidade de um aparato governamental na construção de estratégias multiescalares de desenvolvimento, que promova uma horizontalização nos serviços públicos e desenvolvimento territorial. Desse modo, as políticas públicas no Brasil são definidas como se o país fosse homogêneo, seguisse o mesmo padrão cultural, social, físico, e entre outros, mas sabe-se que o país apresenta uma heterogeneidade riquíssima. Sendo assim, algo que é aplicado em uma determinada região pode não servir para outra, pois, essa provavelmente apresentará diferenciações.

Em busca de uma mudança e integração territorial, surge no cenário brasileiro à proposta de descentralização da ação pública, por meio de políticas com enfoque territorial, com vistas ao desenvolvimento. A Política de Desenvolvimento Territorial (PDT) tem o propósito de adequar às ações governamentais de acordo com a necessidade de cada território, de oferecerem alternativas inovadoras aos problemas encontrados. Criada em 2003, a PDT passou a atuar com base na ideia de territórios, entendendo-os como:

\footnotetext{
Um espaço físico, geograficamente definido, geralmente contínuo, compreendendo cidades e campos, caracterizado por critérios multidimensionais, tais como o ambiente, a economia, a sociedade, a cultura, a política e as instituições, e uma população, com grupos sociais relativamente distintos, que se relacionam interna e externamente por meio de processos específicos, onde se pode distinguir um ou mais elementos que indicam identidade e coesão social, cultural e territorial (BRASIL, 2003, p. 34).
} 
Nesse sentido podemos entender a PDT como uma política pública que contribui para a efetivação da gestão social, a partir do Programa Desenvolvimento Sustentável dos Territórios Rurais (PRONAT), que tem como objetivo geral promover e apoiar iniciativas das institucionalidades representativas dos territórios rurais que busquem o incremento sustentável dos níveis de qualidade de vida da população rural (BRASIL, 2005; 2011). O programa tem como foco a abordagem territorial do desenvolvimento rural, que está alicerçada em três elementos fundamentais: 1) a instituição do território de identidade, cuja criação parte de elementos de identidade, características geográficas, históricas, sociais, ambientais, econômicas, políticas e institucionais comuns a um grupo de municípios; 2) a constituição de uma "nova institucionalidade", que congregue as organizações da sociedade civil e as esferas do poder público, que é o Colegiado Territorial, o qual deverá executar a gestão social do desenvolvimento territorial; e 3) o planejamento territorial, como manifestação da vontade e da visão de futuro dos atores do território, traduzidos em programas, planos e projetos (DELGADO; LEITE, 2011).

Ao referir-se à gestão social, Tenório (2008, p. 158) a define como “[...] processos gerenciais dialógicos nos quais a autoridade decisória é compartilhada entre os participantes da ação", de modo que o adjetivo social de gestão é compreendido como o espaço de relações sociais onde todos têm direito a fala. $\mathrm{O}$ autor refere-se, ainda, à cidadania deliberativa, entendida como uma ação de viés político conduzida pela esfera pública e caracterizada pela ação comunicativa na qual os sujeitos ao apresentarem seus argumentos com bases racionais, devem alcançar um acordo comunicativamente, com base nos melhores argumentos.

Desse modo, o conceito de gestão social, se mostrou como mais adequado para conectar o todo da estratégia de desenvolvimento territorial entendida por Tenório como um "[...] o processo intersubjetivo que preside a ação da cidadania tanto na esfera privada quanto na esfera pública" (TENÓRIO, 2008, p. 36). Na visão de Tenório, a gestão social se efetiva quando os governos institucionalizam práticas de gestão pública, que permita ao cidadão participar ativamente em processos de elaboração de políticas públicas. Processo este, que deve ocorrer desde o seu planejamento inicial, continuando a execução e avaliação de seus impactos sociais (TENÓRIO, 2008).

A gestão social no enfoque territorial refere-se, portanto, aos processos de tomada de decisão dos atores sociais, econômicos e institucionais de um determinado âmbito espacial, sobre a apropriação e uso de territórios tendo em vista a definição de estratégias de desenvolvimento local, regional, territorial. Isso remete aos processos de mudanças estruturais empreendidos por uma sociedade organizada territorialmente, visando dinamizar aspectos sociais e econômicos, com vistas à melhoria da qualidade de vida da população (DALLABRIDA, 2011).

Em complemento ao programa de Desenvolvimento Territorial Rural, o Governo Federal, lançou, em 2008, de acordo com MDA (2011), o Programa Territórios da Cidadania (PTC). Esse teve como objetivo geral a superação da pobreza e das desigualdades sociais no meio rural, inclusive as de gênero, raça e etnia por meio de uma estratégia de desenvolvimento territorial sustentável com: integração de políticas públicas a partir de planejamento territorial; ampliação dos mecanismos de participação social na gestão das políticas públicas; ampliação da oferta e universalização de programas básicos de cidadania; inclusão produtiva das populações pobres e segmentos sociais mais desiguais, tais como trabalhadoras rurais, quilombolas e indígenas. 
Como já mencionado a PDT tem como meta encontrar novos caminhos e soluções inovadoras frente aos problemas sociais e econômicos presentes na sociedade brasileira. Esse propósito não é diferente na Bahia, que está galgando um processo de desenvolvimento na perspectiva territorial. Para tanto, veem elaborando uma série de medidas para fortalecer no estado suas diversidades naturais e sociais. Ao considerar a grande dimensão territorial da Bahia com suas diferenças tanto sociais quanto naturais, entende-se que é importante a construção e inserção da política de desenvolvimento territorial.

Dessa maneira, segundo Serpa (2015), desde 2007 o Estado da Bahia adotou uma nova regionalização em Territórios de Identidade, essa regionalização institucional priorizou uma abordagem sociocultural em substituição a uma abordagem estritamente econômica. $\mathrm{O}$ processo de regionalização se orientou num primeiro momento nas regiões em que predominava a agricultura familiar, posteriormente, os territórios são constituídos também a partir da especificidade de cada região, em que diante das diferenças apresentam traços comuns. "A alteridade regional/territorial passa a ser o critério de fundo da regionalização institucional do estado da Bahia a partir de 2007 [...]" (SERPA, 2015, p. 22).

O Programa Territórios de Identidade foi instituído pelo Decreto 12.354, em (2010), com o objetivo de colaborar com a promoção do desenvolvimento econômico e social dos Territórios de Identidade da Bahia, em consonância com os programas e ações dos governos federal, estadual e municipal. Por meio desse decreto acende a importância do trabalho em conjunto, das esferas Federal, Estadual e Municipal, para a valorização da diversidade histórica, econômica, natural e cultural do território baiano. Tendo sido adotada pela Secretaria de Planejamento do Estado da Bahia (SEPLAN) em 2010, o programa insere os 417 municípios baianos em 27 territórios atualmente. Os Territórios de Identidade são considerados unidades de planejamento do Governo - integrando as políticas públicas e viabilizando na prática as condições e estruturas para que as ações sejam implementadas. A conceituação de território adotada pela SEPLAN, originou-se do MDA. Todos os Territórios de Identidade devem ter a mesma importância, no que se refere ao combate às desigualdades sociais existentes, minimizando assim, os desequilíbrios regionais.

Como resultado do fortalecimento dessa Política Territorial na Bahia, o governo do Estado regulamenta a PDT no Estado, através da Lei No 13214 de 29/12/2014, que estabelece os princípios, as diretrizes e os objetivos da Política de Desenvolvimento Territorial do Estado da Bahia, bem como os seus espaços de participação social e de relação entre as representações dos segmentos da sociedade civil e os Poderes Públicos federal, estadual e municipal.

\section{O TERRITÓRIO DE IDENTIDADE CHAPADA DIAMANTINA}

O Território de Identidade (TI) Chapada Diamantina localiza-se majoritariamente no Centro Sul Baiano, entre as coordenadas aproximadas de $10^{\circ} 45^{\prime}$ a $13^{\circ} 56^{\prime}$ de latitude sul e $40^{\circ} 24^{\prime}$ a $42^{\circ} 37^{\prime}$ de longitude oeste, ocupando uma área aproximada de $32.664 \mathrm{~km}^{2}$ (IBGE, 2011) e correspondendo a quase $5,7 \%$ do território estadual. O mapa que corresponde o TI Chapada Diamantina (figura 2) é formado pelos municípios de Abaíra, Andaraí, Barra da Estiva, Boninal, Bonito, Ibicoara, Ibitiara, Iramaia, Iraquara, Itaetê, Jussiape, Lençóis, 
Marcionílio Souza, Morro do Chapéu, Mucugê, Nova Redenção, Novo Horizonte, Palmeiras, Piatã, Rio de Contas, Seabra, Souto Soares, Utinga e Wagner (SEI, 2015).

Figura 2 - Mapa do Território de Identidade da Chapada Diamantina

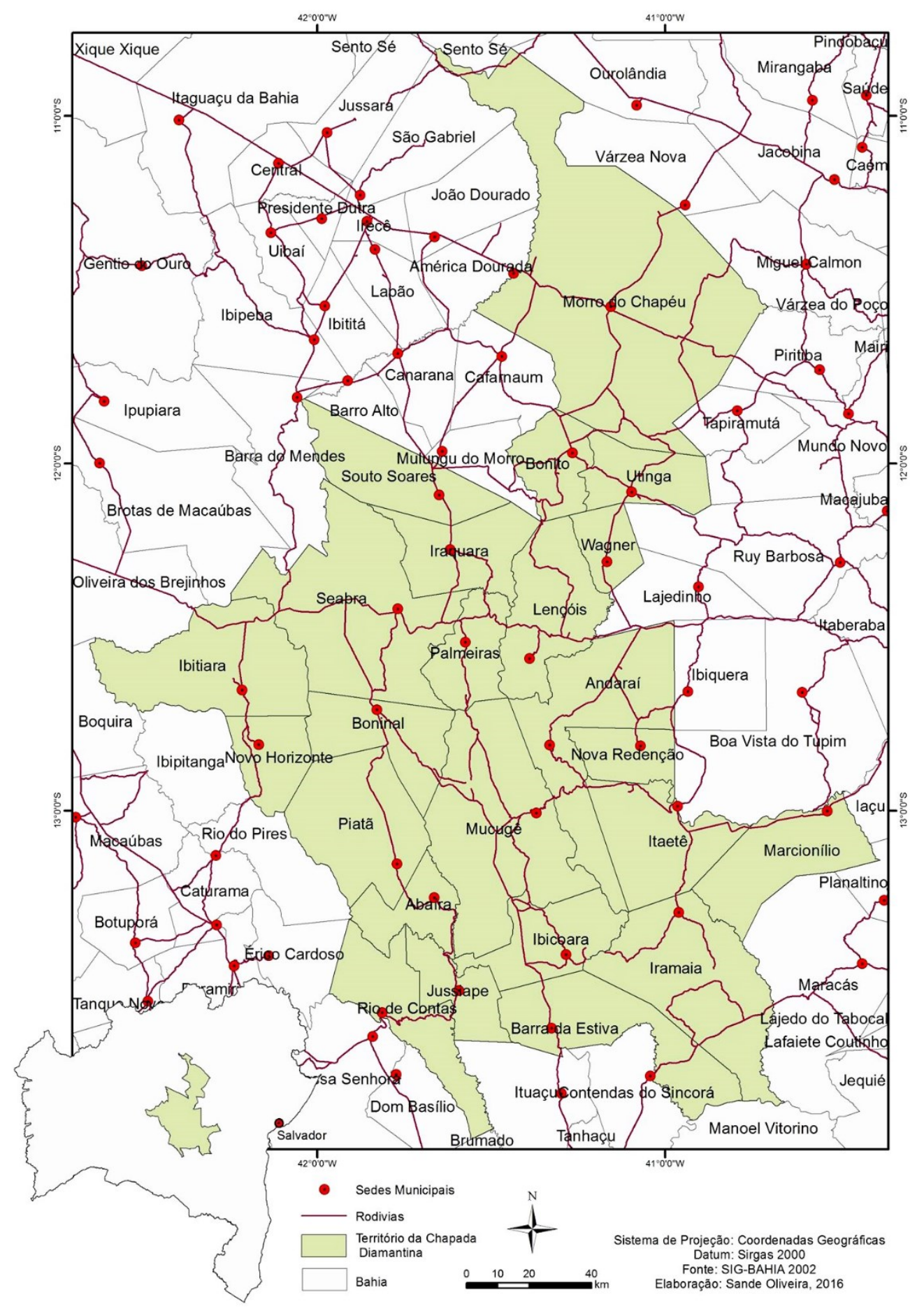

Fonte: CODETER (2016).

DRd - Desenvolvimento Regional em debate (ISSNe 2237-9029) 
O setor de comércio e serviços apresenta uma maior participação no Valor Agregado Bruto (VAB) do Território de Identidade (TI), com 65,8\%, seguido pela agropecuária, com $20,7 \%$, e pela indústria, com 13,5\%. O produto interno bruto (PIB) do TI no ano de 2012 foi de aproximadamente R \$ 2,4 bilhões, representando 1,4\% do PIB estadual. Para o mesmo ano, o PIB per capita do território foi de R \$ 6.372,04, inferior ao da Bahia, que apresentou o valor de R $\$ 11.832,33$. Segundo o censo de 2010, o TI Chapada Diamantina tem 371.864 habitantes, representando $2,65 \%$ da população do estado, sendo 185.722 do sexo masculino e 186.142 do sexo feminino. Sua população é predominantemente rural, visto que apenas 48,4\% de seus habitantes residiam em áreas urbanas. Essa proporção é bem inferior à apresentada pelo estado da Bahia (72,1\%) (SEI, 2015).

Apesar da evolução nos últimos anos, o Índice de Desenvolvimento Humano - IDH nos municípios da Chapada Diamantina ainda se situa abaixo da média da Bahia, de 0,660, conforme levantamento de 2010. Somente oito municípios do território tem IDH superior ao índice 0,600. O Território Chapada Diamantina registra índice de concentração de renda Gini inferior à média da Bahia. No estado, o índice alcança 0,631 , contra 0,557 no território. Quanto mais elevado o Gini, maior a concentração de riqueza. O território ainda registra uma taxa média de analfabetismo em $20,8 \%$, enquanto a média do estado fica em $16,3 \%$. (SEI, 2015).

O território de identidade é destaque no cenário nacional e estadual graças às belezas naturais. Sendo um dos destinos mais procurados no país no que se refere a prática do Ecoturismo, devido a sua grande quantidade de rios, cachoeiras, trilhas, chapadas e morros. A maioria desses atrativos se encontra no Parque Nacional da Chapada Diamantina, área de proteção ambiental mantida pelo Governo Federal. A principal rodovia que liga o TI ao resto do estado é a BR-242, que dá acesso aos municípios do oeste baiano (Barreiras e Luís Eduardo Magalhães), sendo também via de acesso à BR-116 e, consequentemente, a Feira de Santana, Salvador e Região Metropolitana (SEI, 2015).

Percebe-se que Chapada Diamantina, apresenta níveis consideravelmente elevados de desigualdade social, educacional e de renda. O território apesar de ser conhecido nacionalmente pelo Turismo e suas belezas naturais, é um espaço cujo a agricultura é a principal fonte de renda e de movimentação da economia, isso fica claro tanto no VAB, quanto na distribuição da população rural e urbana. Nesse sentido cabe destacar a importância da agricultura familiar enquanto principal fonte de renda das famílias rurais do TI e enquanto produtora de alimentos para o abastecimento dos mercados locais e consequentemente à mesa do trabalhador (CODETER, 2016).

Desse modo, a proposta de promover o planejamento e a autogestão do processo de desenvolvimento sustentável dos territórios rurais e o fortalecimento e dinamização de sua economia trazida pela Política Nacional de Desenvolvimento Rural dos Territórios, por meio do PRONAT, concilia perfeitamente com a realidade do TI Chapada Diamantina, em que há a predominância da agricultura familiar como modo de produção. Nesse contexto, o território da Chapada Diamantina foi um dos primeiros territórios identificado para participar do Programa, juntamente com outros 4 territórios na Bahia, Sisal, Litoral Sul, Velho Chico e Irecê. No ano de 2003 foi criado o Colegiado de Desenvolvimento Territorial (CODETER) do TI Chapada Diamantina, por entidades representativas e movimentos sociais do meio rural. Desde então o TI Chapada Diamantina vem se destacando como um dos territórios mais atuantes na PDT do Estado da Bahia, tendo representação titular na atual composição do 
Conselho Estadual de Desenvolvimento Territorial (CEDETER) e na Coordenação Estadual dos Territórios (CET), sendo também contemplado pelo PTC do MDA como um dos 120 (cento e vinte) Territórios da Cidadania do Brasil.

O CODETER da Chapada Diamantina desde o ano de sua criação, já elaborou e qualificou cinco planos territoriais $(2004,2008,2010,2015,2016)$. Os Planos são uma das principais ferramentas de planejamento, organização social e construção das políticas territoriais, pois, constam nos Planos as demandas, visão de futuro e as estratégias que o Território visa colocar em prática em prol de seu desenvolvimento (CODETER, 2016). Como fruto desse engajamento e ativismo dos atores da Chapada Diamantina, o território obteve a aprovação do Núcleo de Extensão em Desenvolvimento Territorial (NEDET) da Chapada Diamantina, por meio da chamada pública $\mathrm{n}^{\mathrm{o}} 11 / 2014$ do Conselho Nacional de Desenvolvimento Científico e Tecnológico/Ministério do Desenvolvimento Agrário/Secretaria de Políticas para Mulheres. Também conhecido como Projeto Chapadeiros, o NEDET é uma iniciativa desenvolvida no âmbito do Instituto Federal de Educação, Ciência e Tecnologia da Bahia (IFBA), campus Seabra, em parceria direta com o CODETER no intuito de apoiar ações de extensão e de assessoramento técnico ao Colegiado e demais atores do território.

\section{O SISTEMA SYSCHAPADA}

O SysChapada (www.syschapada.ifba.edu.br), cujo o nome provem da junção da abreviação da palavra system (sys) - sistema na lingua inglesa - e do nome do território de identidade da Chapada Diamantina, com intuito de inferir ao usuário, a ideia de um sistema de informações relacionadas ao território da Chapada Diamantina, utiliza-se da abreviação do termo em inglês por questões estéticas e de identidade visual da página. O sistema está situado dentro da problemática explicitada no início do trabalho, de que as ferramentas existentes no âmbito do desenvolvimento territorial, o SGE e o Portal da Cidadania, são sistemas com grande quantidade e fluxos de informações disponíveis, o que acaba tornando os mesmos como ferramentas subutilizadas, pois, não cumprem por completo o seu papel de informar, comunicar e ser acessível ao seu público alvo. Nesse caminho, Allebrandt em seu estudo desenvolvido no território da cidadania Noroeste Colonial-RS, aponta:

\footnotetext{
Os entrevistados no TC-Norc sinalizaram que a gestão do Portal da Cidadania é 'burocrática'. Eles desconhecem um contato no Comitê Gestor Nacional que seja acessível aos membros do CODETER para sanar dúvidas em relação à alimentação do portal, ou até mesmo a conteúdos já existentes. [...] O portal da cidadania foi citado nas entrevistas como um instrumento de comunicação disponível, porém utilizado com pouca frequência (ALLEBRANDT, 2015, p. 129).
}

Embora os idealizadores da Política de Desenvolvimento Territorial tenham concebido o SGE e o Portal da Cidadania como ferramentas de compartilhamento e acesso de dados e informações, é preciso compreender que o público alvo formado principalmente por agricultores familiares, assentados da reforma agrária, quilombolas, indígenas, famílias de pescadores e comunidades tradicionais, carece daquilo que a academia chama de letramento digital, que consiste em justamente saber utilizar e acessar as informações disponíveis nos instrumentos tecnológicos. 
Perante essa situação, o SysChapada surge de uma demanda do Colegiado de Desenvolvimento Territorial, de que fosse construído uma ferramenta digital que permita aos cidadãos da Chapada Diamantina terem fácil acessso às informações do colegiado, seu núcleo diretivo, suas instâncias de gestão, seus representantes e os documentos produzidos por esse colégio, além de disponibilizar ainda uma caracterização geral do território, através de dados dos municípios e outras informações relevantes da região. Partindo dessa necessidade, o projeto em questão busca ser uma alternativa viável, sendo um sistema com uma quantidade enxuta de dados, assegurando assim os princípios da transparência pública e do acesso à informação, e consequentemente auxiliando no bom desenvolvimento da política territorial na Chapada Diamantina.

Para que o desenvolvimento do SysChapada pudesse ter início, ocorreu primeiramente o levantamento de requisitos, conforme sequência definida pelo ciclo de vida adotado para o projeto, o ciclo de vida em cascata. Foram entrevistados coordenador do Colegiado de Desenvolvimento Territorial (CODETER) da Chapada Diamantina e o coordenador do Núcleo de Extensão em Desenvolvimento Territorial (NEDET) da Chapada Diamantina, nesta etapa foram definidas as funcionalidades básicas do software.

Uma vez realizado o levantamento dos requisitos e a sua consequente análise, parte-se para a modelagem do sistema, através da linguagem de modelagem orientada a objetos, Unified Modeling Language (UML). Nesta etapa para a modelagem do sistema se optou pelo uso da representação diagramática, através dos diagramas de casos de uso e de classes. A base para a construção dos diagramas foi a entrevista realizada na etapa de levantamento de requisitos, nela foi possível elencar os atores do site, informação necessária para a construção do diagrama de casos de uso. 
Figura 3 - Diagrama de Casos de Uso do SysChapada.

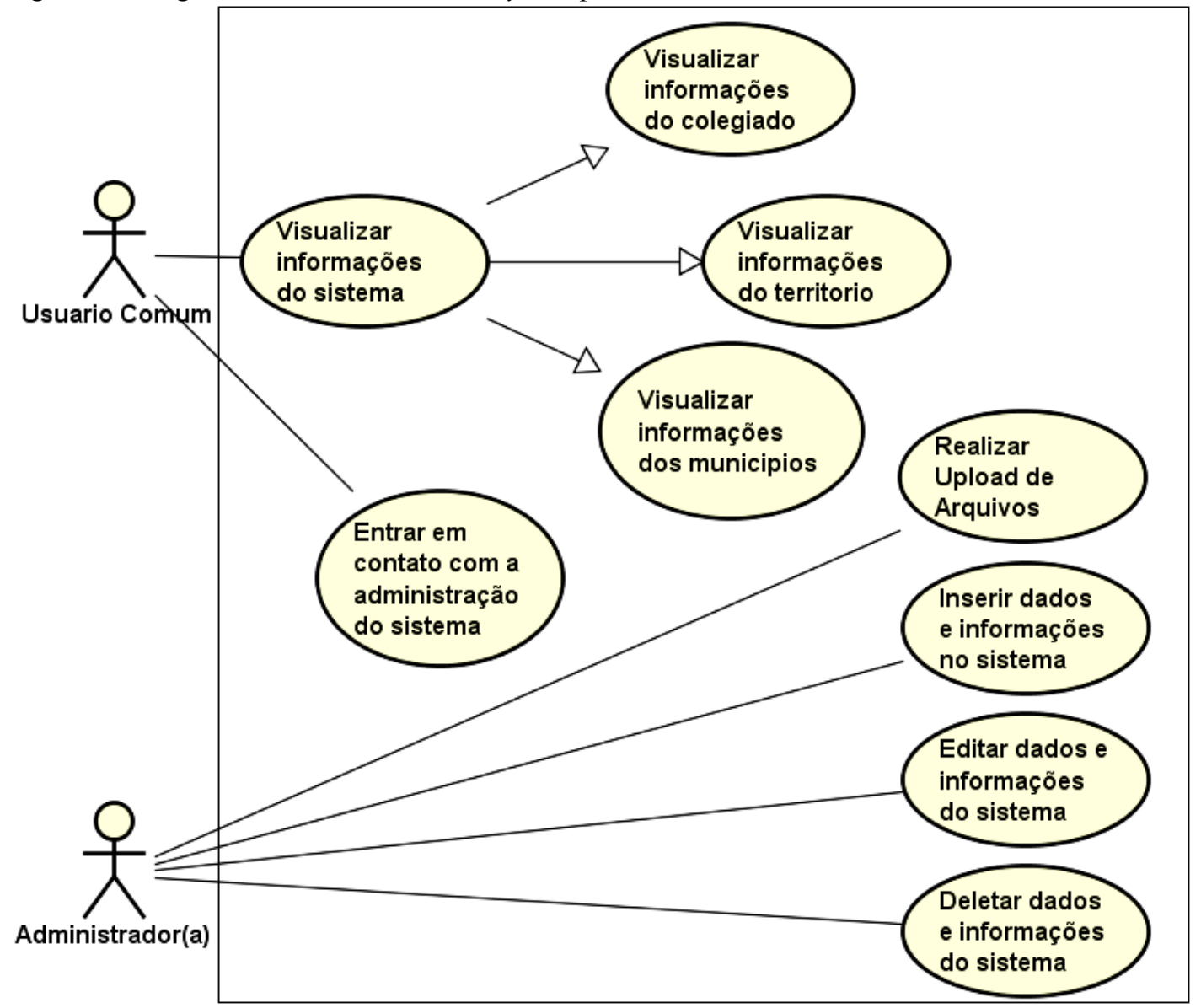

Fonte: Próprio Autor (2017).

O diagrama de casos de uso (figura 5) é composto pelos seguintes atores: o administrador, que é responsável por realizar a inserção, edição e exclusão de registros do banco de dados e também por fazer upload - ato de enviar dados de um computador local para um computador ou servidor remoto - de arquivos para o sistema, e o usuário comum, que é capaz de consultar as informações disponíveis no site e entrar em contato com a administração do website.

Já o diagrama de classes serve para modelar as definições de recursos essenciais à operação correta do sistema. Ele descreve a visão estática do sistema em termos de classes e relacionamentos entre as classes. Com certeza este diagrama é o mais importante em uma documentação de software, onde podemos encontrar as informações sobre métodos, atributos, nome das funções e como serão integradas. 
Figura 4 - Diagrama de Classes do SysChapada

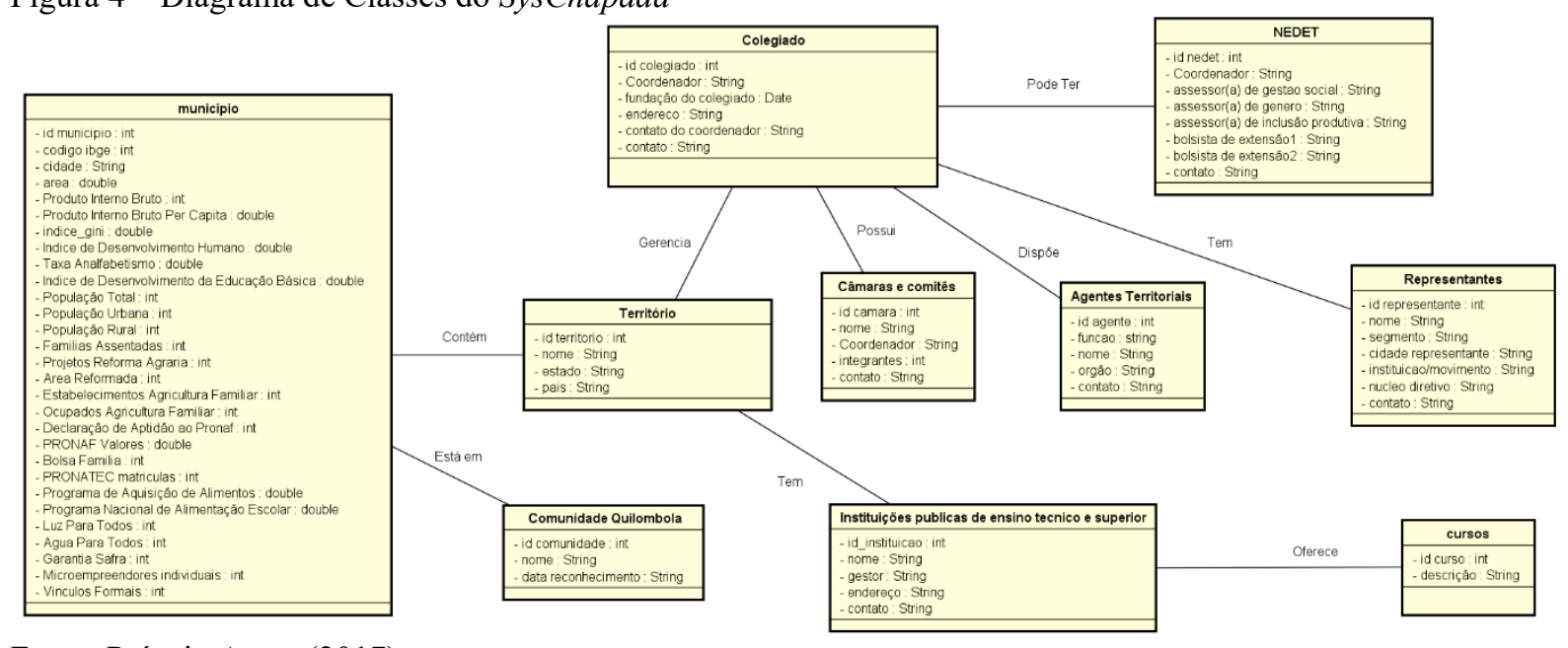

Fonte: Próprio Autor (2017).

O diagrama de classes (figura 4) foi construído por meio de entrevistas realizadas com os coordenadores do CODETER e do NEDET. O arranjo das classes e atributos está alicerçada em duas grandes áreas de representação: as classes e atributos ligados a Política de Desenvolvimento Territorial (PDT) e a as classes e atributos relacionados ao Território de Identidade.

Desse modo, o sistema oferece uma visão completa para o acesso à informação acerca da PDT, através das classes "colegiado", que dispõe de dados básicos sobre a representação máxima dessa política; da classe "representantes", que irá guardar os representantes do colegiado, bem como as informações necessárias dos representantes da sociedade civil e do poder público para os usuários; da classe "câmaras e comitês", que receberá as informações referentes a estas instâncias de apoio ao colegiado e os seus respectivos coordenadores; da classe "agentes territoriais", que tem a função de receber os dados com os agentes disponibilizados pelo Estado para auxiliar na PDT, bem como suas informações funcionais; e por último, a classe "NEDET", que tem em sua estrutura os atributos da composição da equipe do núcleo.

Do outro lado está a caracterização geral do Território, através das especificidades da Chapada Diamantina, levando em conta os fatores sociais, econômicos, educacionais, culturais e agrários. Nessa perspectiva está disposto no diagrama as classes "território", que tem em seus atributos o nome do território e seu pertencimento federativo; a classe "município", cujo os dados a serem preenchidos visam oferecer um panorama dos 24 municípios no que se refere aos indicadores socioeconômicos e educacionais, aos dados demográficos, aos números rurais e agrários, aos indicativos de trabalho e emprego e das políticas públicas do Governo Federal nos municípios da Chapada; a classe "comunidade quilombola", cuja estrutura da classe receberá os dados das Comunidades Quilombolas do Território; e por último, estão as classes "instituições de ensino técnico e superior" e "cursos" que guardarão as informações das instituições de ensino técnico e superiores e os cursos oferecidos por estas.

Definida a parte conceitual do projeto por meio dos diagramas UML e da modelagem do banco de dados, o próximo passo é definir a estrutura gráfica do site, para isso foram 
construídas representações de baixas fidelidade sobre o design visual do SysChapada, representações estas denominadas wireframe ou protótipo, com base nas leis de usabilidade apresentadas por Steve Krug. O wireframe (figura 5) do sistema busca contemplar o acesso rápido e eficaz dos usuários ao sistema, bem como uma melhor visualização do conteúdo procurado, para que dessa forma a navegação e o direcionamento do usuário seja preciso, economizando o tempo disponível e levando-o a opção desejada.

Figura 5 - Wireframe do SysChapada

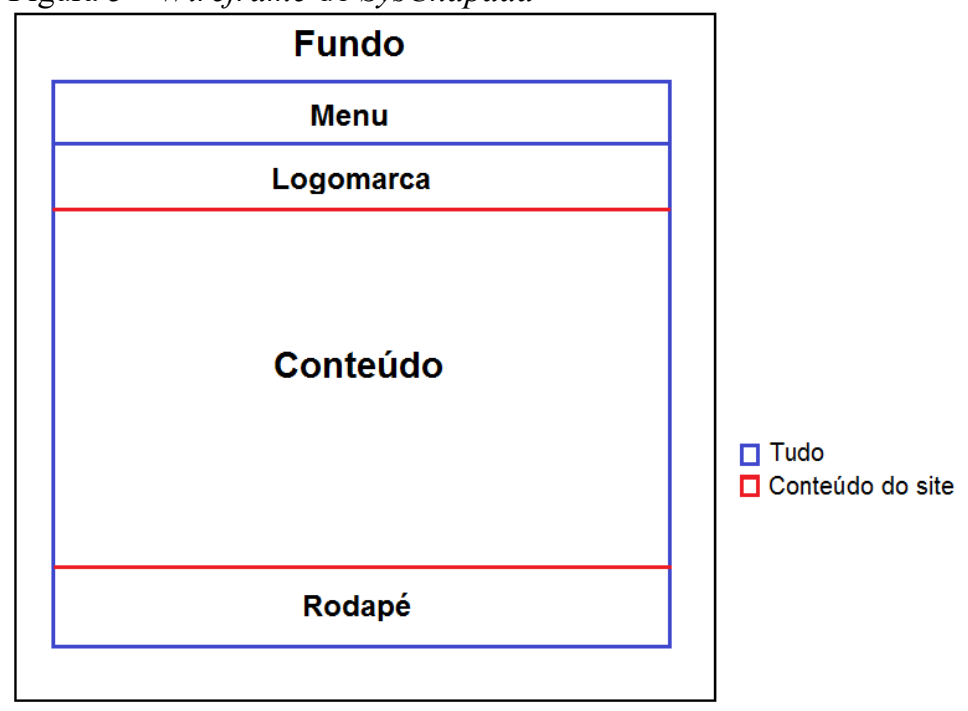

Fonte: Próprio Autor (2017).

A divisão da estrutura do site e seus contêineres seguiu os padrões convencionais utilizados no mercado, optando por valorizar a identidade visual da ferramenta, com a ênfase na logomarca que está abaixo do menu, porém sem perder de vistas a usabilidade do sistema possibilitando que o usuário tenha facilidade para visitar as páginas, devido a boa localização do menu, no centro da representação está o conteúdo que será exibido em cada página da aplicação e logo abaixo, o rodapé, que irá exibir os direitos autorais do sistema, bem como outras informações relevantes.

O modelo de arquitetura escolhido para implementação do sistema SysChapada foi baseado na arquitetura do tipo cliente-servidor (figura 6). Em tal modelo, o acesso dos usuários dar-se-á por meio de solicitações ao servidor web, o qual se comunica com a linguagem de programação do sistema - Hipertext Pre Processor (PHP) -, ativando o seu interpretador que por sua vez interage com o Sistema de Gerenciamento de Banco de Dados, para acesso aos dados armazenados no banco de dados MySQL. 
Figura 6 - Arquitetura Cliente-Servidor

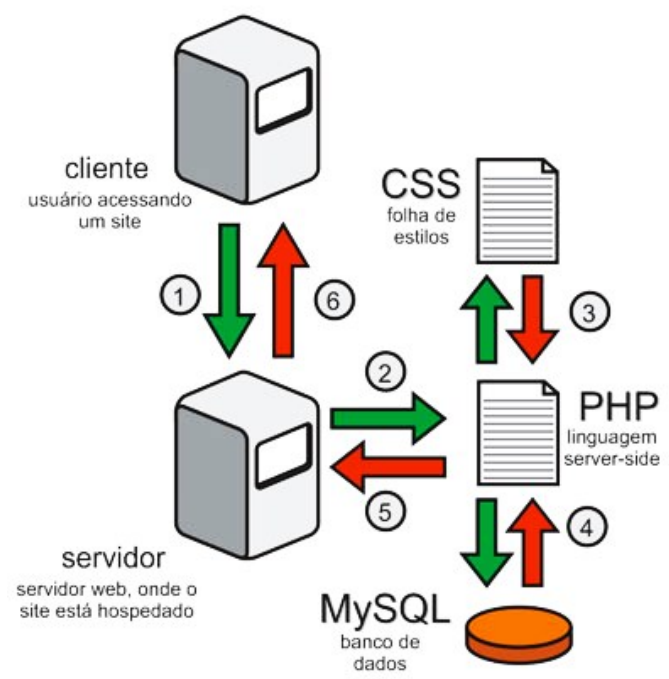

Fonte: Site Carambola Digital ${ }^{4}$

Cumpridas as etapas dos requisitos, análise e desenho, conforme estabelecido pelo ciclo de vida, iniciou-se a criação das telas do sistema SysChapada. Essa criação se deu através da escrita de códigos nas linguagens de marcação de hipertexto - HyperText Markup Language (HTML) -, linguagem em que são escritas as páginas web, com a folha de estilo em cascata - Cascading Style Sheet (CSS) - e a sua biblioteca Bootstrap que permite o desenvolvimento de uma aplicação web responsiva (sites que se adaptam a diferentes tamanhos de tela, se ajustando ao dispositivo do usuário) e com a linguagem JavaScript. A programação visual do site teve como referência o wireframe do sistema e, a partir daí, foram criadas as páginas da aplicação, seguindo os padrões de usabilidade e qualidade conhecidos atualmente.

${ }^{4}$ Fonte: http://www.caramboladigital.com.br/html-e-css-07/. Acesso em 20 mar. 2017 
Figura 7 - Página Inicial do SysChapada
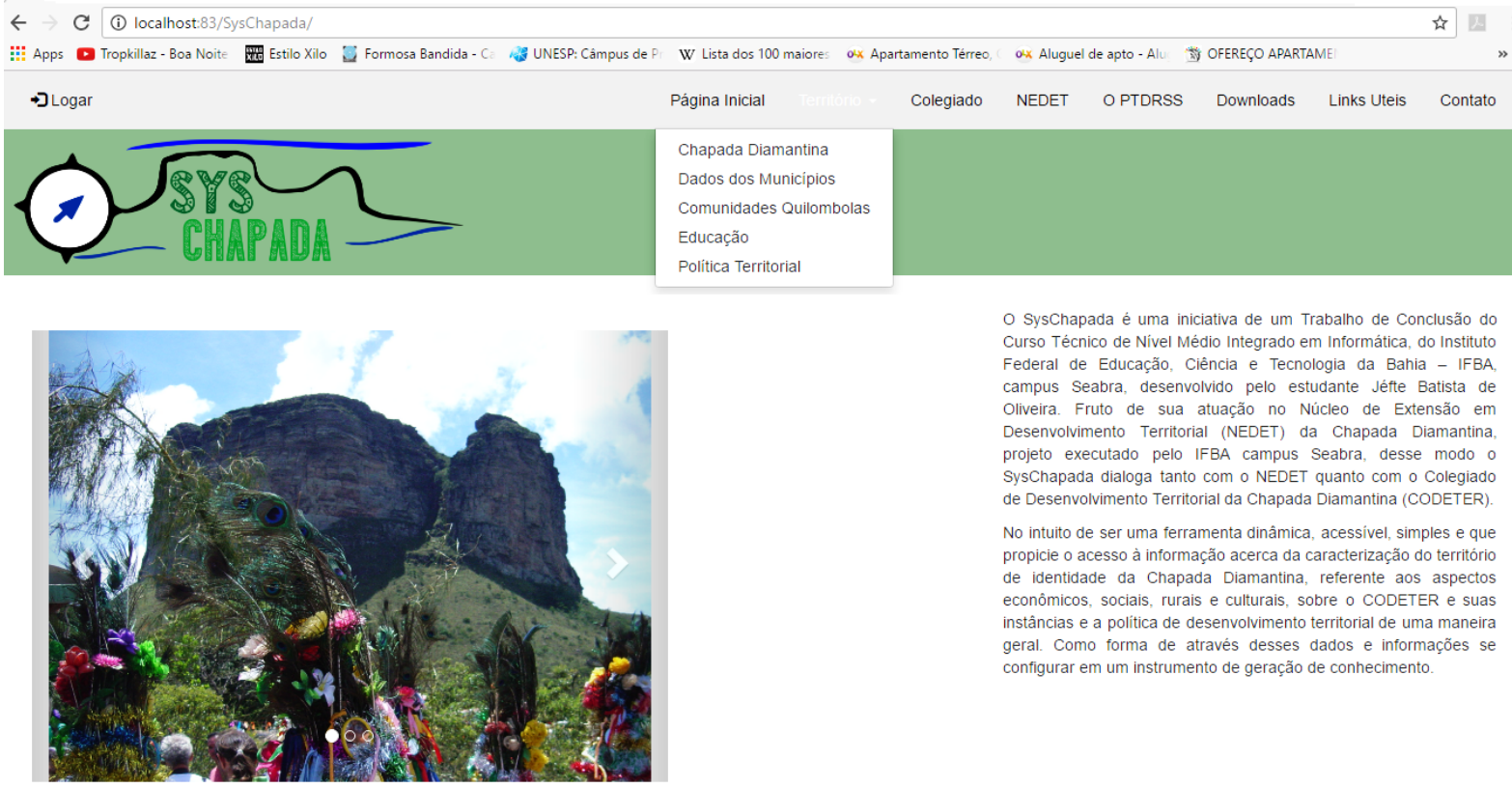

SysChapada é uma iniciativa de um Trabalho de Conclusão do Curso Técnico de Nivel Médio Integrado em Informática, do Instituto Federal de Educação, Ciência e Tecnologia da Bahia - IFBA, campus Seabra, desenvolvido pelo estudante Jéfte Batista de Oliveira. Fruto de sua atuação no Núcleo de Extensão em Desenvolvimento Territorial (NEDET) da Chapada Diamantina, projeto executado pelo IFBA campus Seabra, desse modo o SysChapada dialoga tanto com o NEDET quanto com o Colegiado de Desenvolvimento Territorial da Chapada Diamantina (CODETER). No intuito de ser uma ferramenta dinâmica, acessivel, simples e que propicie o acesso à informação acerca da caracterização do território de Identidade da Chapada Diamantina, referente aos aspectos economicos, sociais, rurais e culturais, sobre O CODETER e suas instânclas e a politica de desenvolvimento territoniar de uma maneira geral. Como forma de atraves desses dados e informaçoes se configurar em um instrumento de geração de conhecimento

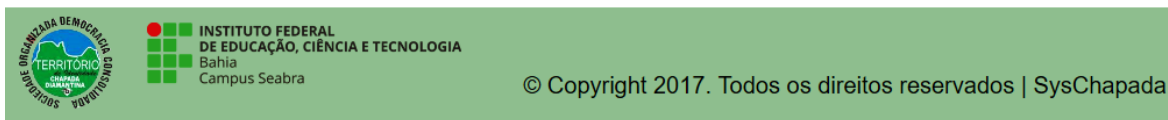

Fonte: Próprio Autor (2017).

A organização da página inicial (figura 7) do SysChapada está disposta de forma que os usuários consigam localizar facilmente as informações desejadas, através do menu, contando ainda um slideshow que traz imagens que buscam representar a diversidade do Território da Chapada Diamantina, bem como uma breve descrição do sistema. Seguindo os princípios de Krug.

Nada importante deve estar a mais de dois cliques de distância' ou 'Fale a língua do usuário' ou mesmo 'Seja consistente'. Isto é [...] 'Não me faça pensar!'. Este é o princípio primordial - o fator de desempate ao decidir se algo funciona ou não em um projeto Web (KRUG, 2006).

Desse modo a organização do website segue a máxima de Krug, em que nada deve estar a mais de dois cliques de distância do usuário, sendo assim o menu está estruturado de maneira que possa ser entendido rapidamente, comtemplando as tabelas existentes no banco de dados e os demais conteudos necessários para o projeto, com as páginas "Chapada Diamantina", "Dados dos Municípios", "Comunidades Quilombolas", "Educação", "Política Territorial", "Colegiado", "NEDET", "O PTDRSS", "Downloads", "Links Úteis" e "Contato".

O uso da linguagem PHP, permitiu criar as funcionalidades do sistema, dentre elas, aquelas que foram definidas no diagrama de casos de uso, como atribuições do administrador(a) do sistema. As funções do administrador(a) são as de cadastrar (insert), editar (update) e excluir (delete) registros do banco de dados, bem como realizar upload de arquivos para a aplicação. Essas operações só são possíveis através de um login no sistema, com valores de usuário e senha pré-definidos para que somente o administrador tenha acesso a essas ações 
Figura 8 - Página Inicial do Administrador(a) do SysChapada
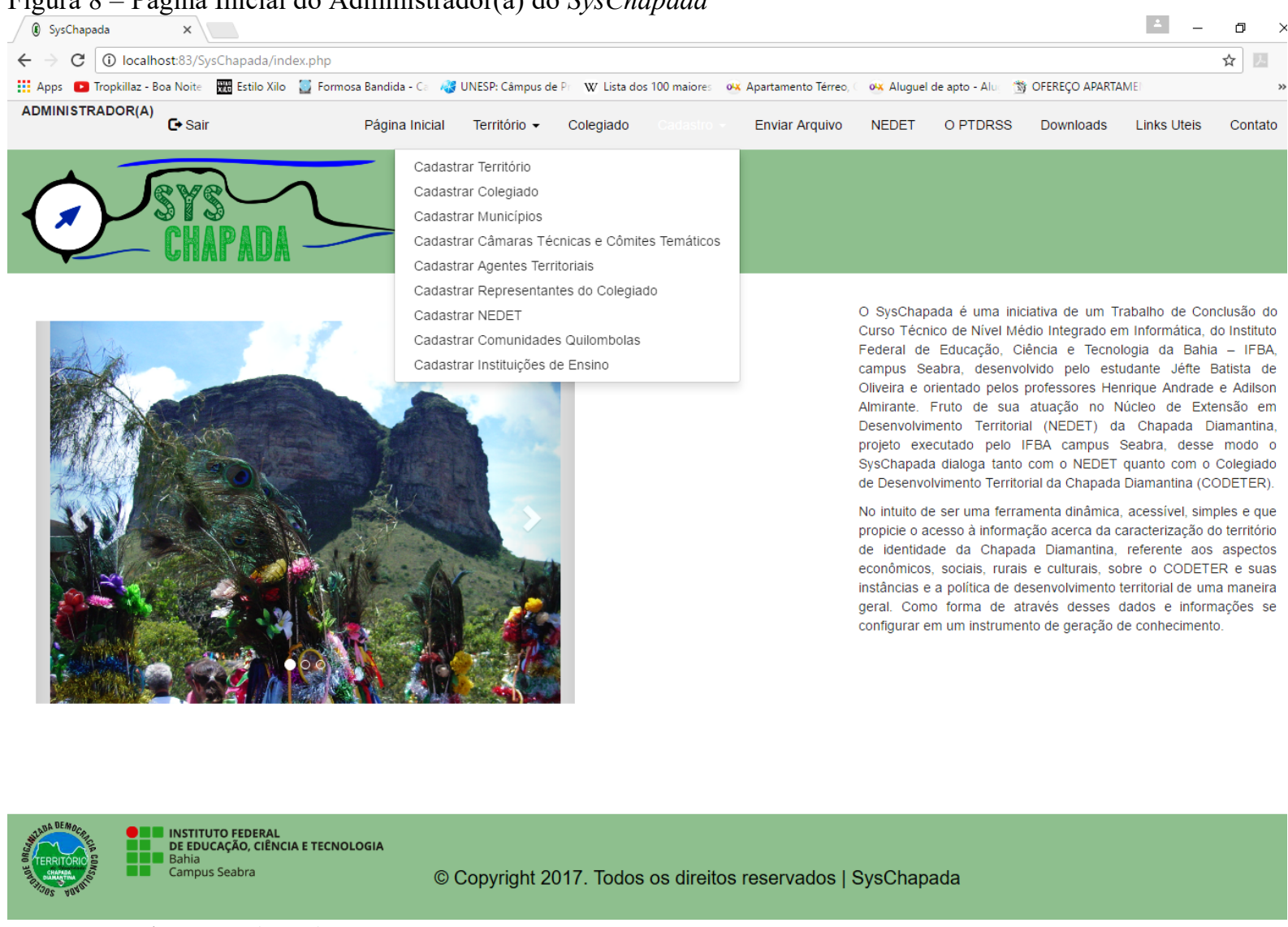

Fonte: Próprio Autor (2017).

A página inicial do administrador (figura 8) possui um menu diferenciado que permite o cadastro de informações nas tabelas do banco e o envio de arquivos, páginas estas ocultas ao usuário comum. Desse modo para registrar novas informações no banco de dados, basta clicar na aba cadastro e no segmento que deseja inserir os valores, essa inserção ocorre através de um formulário em que cada campo deste representa um atributo da tabela de banco de dados, ao ser preenchido e enviado o formulário, o PHP se comunica com o $M y S q l$ inserindo esses registros no banco do sistema. Essa integração entre a linguagem de programação e o SGBD possibilita também que o administrador realize as operações de editar e excluir informações do banco de dados. A linguagem de Programação PHP é responsavel também por selecionar os dados do banco de dados e exibir nas páginas, através da conexão com o SGBD e pela função de enviar e-mails quando o usuário preencher um formulário de contato com a administração do sistema.

Passado todo o processo de desenvolvimento do software, iniciou-se a etapa de testes, em que foram realizadas e testadas todas as funções descritas que constituem o software. Havendo necessidade de correção ou apresentação de uma falha durante o desenvolvimento do software, o ciclo de vida permite voltar diretamente na etapa de desenvolvimento anterior. Tendo realizado todos os testes, correções e abordado todos os processos presentes no ciclo de desenvolvimento, iniciou-se a parte de implantação do sistema na internet, através da hospedagem no domínio (www.syschapada.ifba.edu.br). 


\section{CONSIDERAÇÕES FINAIS}

A Política de Desenvolvimento Territorial criada a nível nacional em 2003 pela SDT e o MDA e regulamentada pelo PRONAT e PTC, adotada pelo Estado da Bahia em 2007, no âmbito Secretaria do Planejamento da Bahia se configura como um importante avanço na descentralização do estado brasileiro, promovendo a cidadania e o pleno exercício da democracia participativa. No que se refere a política de desenvolvimento territorial no âmbito do território de identidade Chapada Diamantina, é notável a sua contribuição como instrumento de gestão social através do colegiado e suas instâncias, onde é possível planejar, gerir e fiscalizar as políticas públicas referentes as demandas do território, fortalecendo a participação e o engajamento da população regional, trazendo em todos esses anos inúmeros benefícios a região em forma de investimentos públicos.

Para a execução dessa política pública a informação e a comunicação são essenciais para a sua efetivação e o alcance aos resultados esperados, o meio mais eficaz para a realização dessa comunicação é a internet, através de ferramentas de Tecnologia da Informação e Comunicação (TIC). Porém é perceptível que as TICs enfrentam barreiras dentro desse processo, pois, as ferramentas disponíveis atualmente, o SGE e o Portal da Cidadania são subutilizados, pois seu poder de alcance ainda não atinge todos os atores e sujeitos dos territórios.

Desse modo compreende-se que o SysChapada (www.syschapada.ifba.edu.br) possui todos os atributos para preencher essa lacuna a nível local, sendo uma ferramenta idealizada a partir da vivência in loco no Colegiado de Desenvolvimento Territorial da Chapada Diamantina e de entrevistas com peças chaves da política territorial na Chapada. Com base nessa vivência e nos requisitos levantados, o desenvolvimento do sistema se deu de forma a abrigar as informações necessárias sobre o território e sobre toda estrutura derivante do colegiado, informações estas planejadas para estarem bem localizadas e com facilidade de acesso, objetivando que as TICs entrem de vez na rotina da política de desenvolvimento territorial na Chapada Diamantina.

O SysChapada pretende ser um modelo de sucesso como um instrumento de potencialização do desenvolvimento territorial na Chapada Diamantina, através da acessibilidade, inovação e usabilidade do sistema, como forma de incentivar, a partir da experiência a ser obtida com a implantação do website, que as estruturas responsáveis pelo desenvolvimento territorial nos territórios brasileiros adotem iniciativas semelhantes, com essa caracterìstica enxuta de dados e facilidade no acesso às informações, visando contribuir para a melhoria da complexa política de desenvolvimento territorial, através do uso das tecnologias disponíveis atualmente. 


\section{REFERÊNCIAS}

ALLEBRANDT, S. L. et al. A Utilização das TICs no Âmbito do Território da Cidadania Noroeste Colonial e suas Contribuições para as Práticas de Gestão Social. In: VI ENCONTRO NACIONAL DE PESQUISADORES EM GESTÃO SOCIAL, São Paulo, 2012. Anais... São Paulo, 2012.

ALLEBRANDT, S. L; BENSO, A; DE OLIVEIRA, V. G. Interfaces entre a Comunicação e a Gestão Social no Contexto do Desenvolvimento Territorial: um estudo do território da cidadania noroeste colonial do Rio Grande do Sul. Revista de Ciências da Administração, Florianópolis, p. 120-133, dez. 2015.

BRANDÃO, C. Território e Mudanças no "Padrão de sociabilidade" no Brasil. In: ORTEGA, Antonio César. Território, Políticas Públicas e Estratégias de Desenvolvimento.

Campinas-SP: Editora Alínea, 2007, p. 17-40.

BRASIL. Ministério do Desenvolvimento Agrário (MDA). Referências para o

Desenvolvimento Territorial Sustentável. 2003. Disponível em: $<\underline{\mathrm{http}} / / / \mathrm{www} \cdot \mathrm{mda}$.gov.br/ sitemda/sites/sitemda/files/user_arquivos_64/arquivo_253.pdf $>$. Acesso em: 28 set. 2016.

Referências para uma estratégia de desenvolvimento rural sustentável no Brasil. Brasília: SDT/MDA, 2005. (Série Documentos SDT; n. 1)

Programa Desenvolvimento Sustentável de Territórios Rurais PRONAT:

Balanço da Gestão 2003-2010. Brasília: SDT; MDA, 2011.

CASTELLS, M. A Sociedade em Rede. São Paulo: Paz e Terra, 1999. v. 1.

COLEGIADO DE DESENVOLVIMENTO TERRITORIAL DA CHAPADA

DIAMANTINA (CODETER). Plano Territorial de Desenvolvimento Rural Sustentável e Solidário do Território Chapada Diamantina. Seabra: CODETER, 2016.

DALABRIDA, V. R. Concepções teóricas que sustentam o debate sobre descentralização político-administrativa. In: DALLABRIDA, Valdir Roque (Org.). Governança Territorial e Desenvolvimento: descentralização político-administrativa, estruturas subnacionais de gestão do desenvolvimento e capacidades estatais. Rio de Janeiro: Garamond, 2011. p. 40-52.

DELGADO, N. G.; LEITE, S. P. Gesstão social e novas institucionalidades no âmbito da Política de desenvolvimento territorial. In: DELGADO, N. G.; LEITE, S. P. Políticas públicas, atores sociais e desenvolvimento Territorial no Brasil. Brasília: IICA. Série Desenvolvimento Rural Sustentável, v.14, 2011, p. 89-130.

KRUG, S. Não me faça pensar!: uma abordagem de bom senso à usabilidade na web. Rio de Janeiro: Alta Books, 2006.

MARTINO, L. M. S. Teoria das mídias digitais: linguagens, ambientes, redes. Petrópolis, RJ: Vozes, 2014. 
SEI. Perfil dos Territórios de Identidade Bahia. Salvador: SEI, 2015. 3 v. (Série territórios de identidade da Bahia, v. 1).

SERPA, A. S. P. Territórios de identidade da Bahia: regionalização institucional e políticas de desenvolvimento cultural e territorial. In: SERPA, A. (Org.). Territórios da Bahia regionalização, cultura e identidade. 1ed.Salvador: EDUFBA - Editora da Universidade Federal da Bahia, 2015, v. 1, p. 19-37.

TENÓRIO, F. G. Um espectro ronda o terceiro setor, o espectro do mercado. 3. ed. Ijuí: Editora da Unijuí, 2008.

Artigo recebido em: 14/07/2017

Artigo aprovado em: 06/10/2017 